\title{
REVIEW
}

\section{Systems medicine and the integration of bioinformatic tools for the diagnosis of Alzheimer's disease}

\author{
Matej Orešičl* ${ }^{*}$, Jyrki Lötjönen² and Hilkka Soininen ${ }^{3}$
}

\begin{abstract}
Because of the changes in demographic structure, the prevalence of Alzheimer's disease is expected to rise dramatically over the next decades. The progression of this degenerative and terminal disease is gradual, with the subclinical stage of illness believed to span several decades. Despite this, no therapy to prevent or cure Alzheimer's disease is currently available. Early disease detection is still important for delaying the onset of the disease with pharmacological treatment and/or lifestyle changes, assessing the efficacy of potential therapeutic agents, or monitoring disease progression more closely using medical imaging. Sensitive cerebrospinal-fluid-derived marker candidates exist, but given the invasiveness of sample collection their use in routine diagnostics may be limited. The pathogenesis of Alzheimer's disease is complex and poorly understood. There is thus a strong case for integrating information across multiple physiological levels, from molecular profiling (metabolomics, lipidomics, proteomics and transcriptomics) and brain imaging to cognitive assessments. To facilitate the integration of heterogeneous data, such as molecular and image data, sophisticated statistical approaches are needed to segment the image data and study their dependencies on molecular changes in the same individuals. Molecular profiling, combined with biophysical modeling of molecular assemblies associated with the disease, offer an opportunity to link the molecular pathway changes with cell- and tissue-level physiology and structure. Given that data acquired at different levels can carry complementary information about early Alzheimer's disease pathology, it is expected that their integration will improve early detection as well as our understanding of the disease.
\end{abstract}

*Correspondence: matej.oresic@vtt.f

'VTT Technical Research Centre of Finland, Espoo, Fl-02044 VTT, Finland Full list of author information is available at the end of the article

\section{Background}

The health of populations in developed countries has never been better. Within the past century, the life expectancy of humans has increased from 40 years to 74 years. Correspondingly, the public health burden has shifted from infectious diseases to autoimmune diseases [1] and to diseases associated with lifestyle and aging, such as diabetes, cardiovascular disease, cancer and Alzheimer's disease (AD).

$\mathrm{AD}$ is the most common form of dementia. Because age is a major risk factor of $A D$, the prevalence of this incurable, degenerative and terminal disease is expected to rise dramatically over the next decades. It is estimated there will be over 80 million AD patients by 2050 [2-4]. Given the change in demographic structure and the rise of life expectancy in developing countries, AD is likely to have a major socioeconomic impact.

The progression of $\mathrm{AD}$ is gradual, with the subclinical stage of illness believed to span several decades $[5,6]$. The pre-dementia stage, also termed mild cognitive impairment $(\mathrm{MCI})$, is characterized by subtle symptoms that may affect complex daily activities. These include memory loss, impairment of semantic memory and problems with executive functions, such as attentiveness, planning, flexibility and abstract thinking [6]. MCI is considered as a transition phase between normal aging and $\mathrm{AD}$. MCI confers an increased risk of developing $\mathrm{AD}$ [7], although the state is heterogeneous with several possible outcomes, including even improvement back to normal cognition [8].

Despite there being no currently available therapy to prevent $\mathrm{AD}$, early disease detection would still be of utmost importance for delaying the onset of the disease with pharmacological treatment and/or lifestyle changes, assessing the efficacy of potential AD therapeutic agents, or monitoring disease progression more closely using medical imaging. Recent research has thus concentrated on obtaining biomarkers to identify features that differentiate between the individuals with $\mathrm{MCI}$ who will develop $\mathrm{AD}$ (progressive $\mathrm{MCI}$ ) and individuals with stable MCI and healthy elderly people. 


\section{Towards molecular markers of AD}

$\mathrm{AD}$ is characterized by deposition of amyloid $\beta(\mathrm{A} \beta)$ in the extracellular space. Given that the allele $\varepsilon 4$ of the apolipoprotein $\mathrm{E}$ gene (APOE4), the major genetic risk factor of $\mathrm{AD}$ [9], leads to excess $\mathrm{Ab}$ accumulation before the first symptoms of $\mathrm{AD}[10]$, it was believed that $\mathrm{A} \beta$ also has a pathogenic role [11]. However, it was later shown that $A \beta$ accumulation in plaques is insufficient to cause the neuronal cell death observed in $\mathrm{AD}$, and that neuronal protein tau is essential for neurodegeneration in AD $[12,13]$.

The 40- or 42-peptide amyloid $\beta\left(\mathrm{A} \beta_{1-40 / 42}\right)$, total tau and tau phosphorylated at Thr181 ( $\left.\mathrm{P}-\operatorname{tau}_{181 \mathrm{P}}\right)$, all of which can be measured from cerebrospinal fluid (CSF), are well established markers of AD [14]. A recent study [15] used an unsupervised mixture modeling approach, independent of AD diagnosis, to identify a molecular signature derived from a mixture of $A \beta_{1-42}$ and $\mathrm{P}-$ tau $_{181 \mathrm{P}}$ that was associated with $\mathrm{AD}$. The $\mathrm{AD}$ signature identified subjects who progress from MCI to AD with high sensitivity and was surprisingly also present in a third of cognitively normal subjects, suggesting that AD pathology may occur earlier than previously thought.

CSF has severe drawbacks for routine diagnosis because of the invasiveness and potential side effects of sample collection. However, attempts to use $A \beta$ or tau as measured from plasma as potential predictive markers of $\mathrm{AD}$ have so far not been successful [16-18]. Among the available non-invasive techniques, brain imaging methods, such as magnetic resonance imaging or positron emission tomography, can identify cerebral pathologies specifically associated with early progression to AD $[18,19]$. At present, it is unclear how atrophy in the hippocampus and hypometabolism in the inferior parietal lobules, as observed in these studies, relate to the disease pathophysiology and the existing CSF-derived markers.

\section{High-throughput strategies to identify novel blood-based biomarkers}

The 'omics' revolution has given us the tools needed for a discovery-driven strategy to identify new molecular biomarkers from biofluids, cells or tissues. Lessons have been learned about the statistical and study design precautions needed when applying such strategies of measuring large numbers of molecular components $[20,21]$. The major advantage of high-throughput approaches over more targeted hypothesis-driven strategies is their capacity to collect large amounts of information about a specific phenotype or disease condition in an unbiased manner.

Recent quantitative analysis of 120 plasma proteins [22] identified 18 signaling proteins as potential predictive biomarker candidates, which were mainly associated with reduced hematopoiesis and inflammation during presymptomatic $\mathrm{AD}$. In a subsequent larger serum proteomics study by another research team [23], a multiplex protein immunoassay was used to classify AD and controls with high sensitivity and specificity. Notably, the overlap of the marker proteins between the two studies was minimal, and neither of the studies [22,23] were validated in an independent cohort. Blood mononuclear cells have also been considered as a potential source of biomarkers. Preliminary studies using transcriptional and microRNA profiling in AD patients and healthy controls suggest that a distinct ADassociated expression signature can be identified [24,25]. The major changes in blood mononuclear cells include diminished expression of genes involved in cytoskeletal maintenance, DNA repair and redox homeostasis.

Profiling of small molecules (metabolites) is also a promising way to search for new AD biomarkers. Concentration changes of specific groups of circulating metabolites may be sensitive to pathogenically relevant factors, such as genetic variation, diet, age or gut microbiota [26-29]. The study of high-dimensional chemical signatures as obtained by metabolomics may therefore be a powerful tool for characterization of complex phenotypes affected by both genetic and environmental factors [30]. No metabolic markers have been reported so far for $\mathrm{AD}$, but several projects aiming to discover serum-derived metabolic markers are ongoing, including HUSERMET [31] and PredictAD [32].

\section{Towards systems medicine in AD}

Large amounts of information gathered by various highthroughput technologies come at a price. The data, usually corresponding to different aspects of disease pathology, need to be integrated in a meaningful way. Such data integration does not encompass only informatics and statistics; for example, it includes the development of tools not only for storing and mining the data, but also modeling of the data in the context of disease pathophysiology. In $\mathrm{AD}$, the adoption of a systems approach is particularly challenging since even at the molecular level the disease pathogenesis is highly complex, covering multiple spatial and temporal scales. As discussed below, this complexity demands that studies look beyond the pathways.

The genetics of late-onset $\mathrm{AD}$ is complex, although several of the common risk alleles other than $A P O E$ are involved in production, aggregation and removal of $A \beta$ [33]. Several of the associated single nucleotide polymorphisms produce a synonymous codon change; that is, without any change in the corresponding protein sequence $[33,34]$. Such synonymous codon changes may not affect gene expression but can affect protein folding and thus the structure and function of the protein [35] by affecting translational accuracy or co-translational 
folding and thus formation and stabilization of protein secondary structure [36].

The importance of understanding the structural and spatial context of $\mathrm{AD}$-associated proteins and peptides is underlined by recent studies of truncated $A \beta$ fragments $\left(\mathrm{A} \beta_{17-40 / 42}\right.$ [37] and $\left.\mathrm{A} \beta_{11-40 / 42}[38]\right)$, which are nonamyloidogenic and thus were believed to be harmless bystanders in amyloid plaques found in AD. Molecular dynamics simulations of truncated $A \beta$ peptides, followed up by functional studies, suggest that these peptides are mobile in biological membranes and may dynamically form ion channels [39]. Such ion channels may be toxic, as they affect the uptake of ions such as calcium into the cells. The reason that they can appear with aging, in some individuals, remains to be established. One possible explanation is the varying composition of neuronal lipid membranes, specifically plasmalogens, ether phospholipids that are enriched in polyunsaturated fatty acids and are abundant in brain [40,41]. Plasmalogens affect membrane fluidity and protein mobility $[40,42]$ and they are found to be diminished in early $\mathrm{AD}$ [43-45] and in normal aging [46]. In addition, plasmalogens, via their vinyl-ether bond, act as endogenous antioxidants to protect cells from reactive oxygen species, and their reduction in $\mathrm{AD}$ is thus in line with the hypothesis implicating the role of oxidative stress in $\mathrm{AD}$ pathogenesis [47]. Taking these results together, one would expect that age-related and disease-related changes in membrane lipid composition would also affect the mobility of $A \beta$ peptides, including dynamics of their self-assembly.
Lipidomics tools are now available for detailed studies of molecular lipids in cells and biofluids [48]. Molecular profiling, combined with biophysical modeling of membrane systems - for example, to study $\beta$-sheet self assembly [49,50], lipid membranes [51] or lipoproteins [52] - thus offer an opportunity to link the molecular pathway changes with cell- and tissue-level physiology and structure. This may not only lead to new concepts in disease pathogenesis, but also suggest new diagnostic and therapeutic avenues.

\section{Bioinformatics tools enabling a systems medicine approach to AD}

Many tools are available for mining of heterogeneous biological data, although the focus of such tools and the challenges being addressed by them have largely been in the domains of molecular interactions and biological pathways [53]. There is still a gap between the molecular representations of disease-related processes and the clinical disease. In this context, the measurement of traits that are modulated but not encoded by the DNA sequence, commonly referred to as intermediate phenotypes [54], may be of particular interest. These intermediate phenotypes not only include biochemical, genomic or functional traits, as discussed above, but also an individual's microbial (gut microflora) and social traits. The bioinformatic strategies to manage the disease-associated genetic, molecular and phenotypic data would thus aim to link the biological networks with specific intermediate phenotypes relevant to clinical disease by using a suite of models (Figure 1). The models,

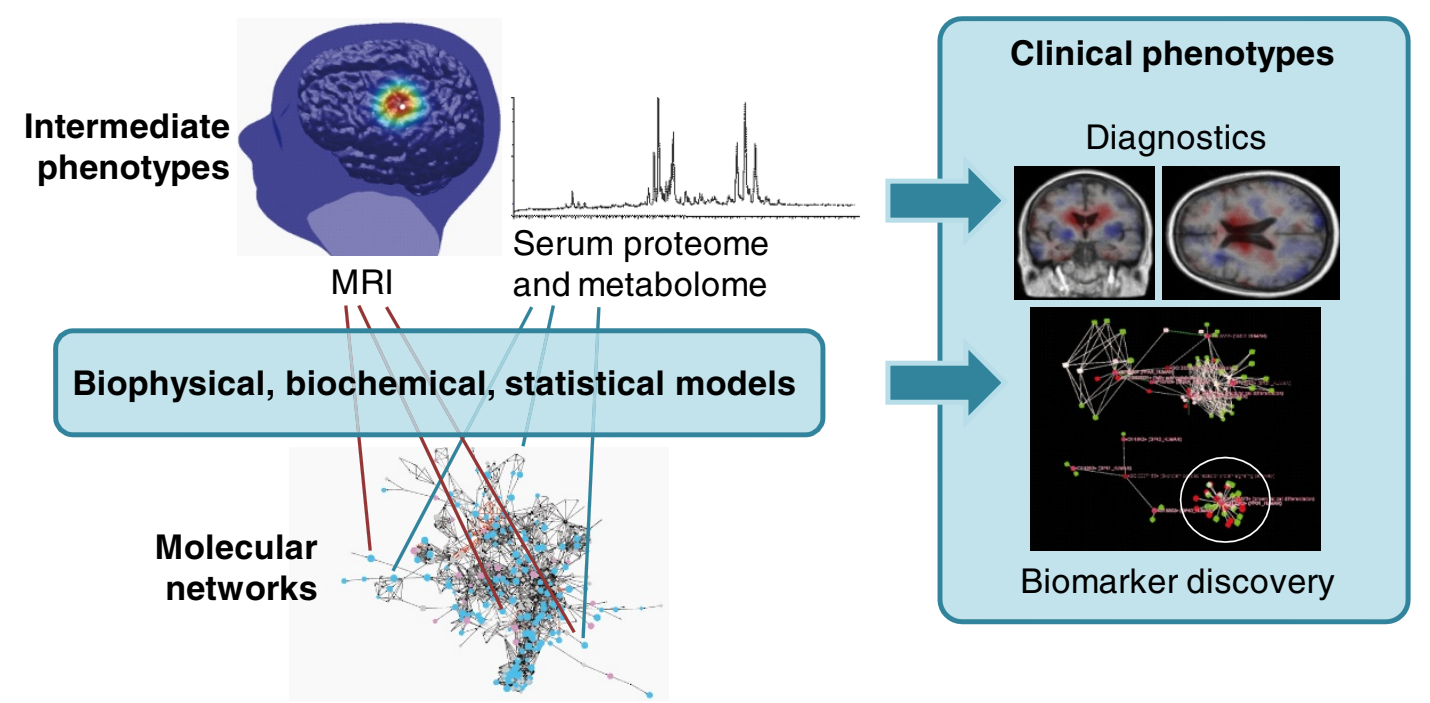

Figure 1. A conceptual bioinformatic framework for enabling biomarker discovery and diagnosis in Alzheimer's disease. The biophysical, biochemical and statistical models are used to integrate information from intermediate phenotypes, such as those obtained from magnetic resonance imaging (MRI) or from serum metabolomics, with the molecular networks. The models relate changes in specific components of the networks with the specific changes in measured intermediate phenotypes (red and blue lines, respectively). These models then inform biomarker discovery and thus diagnosis because they can be used to predict clinical phenotypes from intermediate phenotypes and biomarkers. 
which could be, for example, biophysical or statistical, as described above, together with the intermediate phenotype data, could be used for discovery of new biomarkers of pathophysiological relevance.

Intermediate phenotypes, such as brain image data or serum metabolomic profiles, may also facilitate linking of the findings from experimental disease models with clinical phenotypes. This is particularly relevant for diseases in which animal models are difficult to validate, such as in diseases of the central nervous system. One recent example is a metabolomic study of Huntington's disease [55], for which early disease markers were sought in patients and a transgenic mouse model. Clear differences in metabolic profiles between transgenic mice and wild-type littermates were observed, with a trend for similar differences between human patients and control subjects. The data thus raise the prospect of a robust molecular definition of progression of Huntington's disease before symptom onset and, if validated in a genuinely prospective manner, these biomarker trajectories could facilitate the development of useful therapies for this disease. A similar strategy could also be useful in the studies involving transgenic mouse models of $\mathrm{AD}[56]$.

\section{Conclusions}

The pathogenesis of $\mathrm{AD}$ is complex and there is a strong case for integrating information across multiple physiological levels, from molecular profiling (metabolomics, lipidomics, proteomics and transcriptomics) and brain imaging to cognitive assessments. The adoption of a systems approach to study AD will demand integration of heterogeneous data (such as molecular and image data) and studies of disease-associated molecules and their assemblies beyond the pathway-centric view. To address data integration, sophisticated approaches are needed to segment the image data [57] and study their dependencies on molecular changes in the same subjects. To take studies beyond pathways, computational models are needed to study $\mathrm{AD}$-associated molecules and their interactions in the spatial and temporal context. Given that data acquired at different levels may carry complementary information about early $\mathrm{AD}$ pathology, it is expected that their integration will improve early detection as well as our understanding of the disease.

\section{Abbreviations}

$A \beta$, amyloid $\beta ; A D$, Alzheimer's disease; CSF, cerebrospinal fluid; $M C l$, mild cognitive impairment.

\section{Competing interests}

The authors declare that they have no competing interests.

\section{Authors' contributions}

$\mathrm{MO}$ conceived and wrote the manuscript. JL and HS critically reviewed the manuscript and contributed to its writing.

\section{Author information}

$\mathrm{MO}$ is a Research Professor of systems biology and bioinformatics. His main research areas are metabolomic applications in biomedical research and integrative bioinformatics. He coordinates the European project ETHERPATHS [58], which aims to understand how diet modulates lipid homeostasis, specifically ether lipid metabolism. JL is senior research scientist in data mining. His main research interests are in medical image analysis and decision support systems. He is currently coordinating the European project PredictAD [32] aiming to find efficient biomarkers and their combinations for allowing objective and efficient diagnostics in AD. HS is a Professor of neurology. Her main research field is Alzheimer's disease, specifically genetic and life style risk factors, biomarkers and magnetic resonance imaging. She is a partner in EU projects PredictAD and LIPIDIDIET.

\section{Acknowledgements}

This work was funded under the 7th Framework Programme by the European Commission: EU-FP7-ICT-224328-PredictAD (From patient data to personalized healthcare in Alzheimer's disease; PredictAD; to MO, JL and HS) and EU-FP7KBBE-222639-ETHERPATHS (Characterization and modeling of dietary effects mediated by gut microbiota on lipid metabolism; ETHERPATHS; to MO).

\section{Author details}

'VTT Technical Research Centre of Finland, Espoo, FI-02044 VTT, Finland. ${ }^{2} V T T$ Technical Research Centre of Finland, Tampere, FI-33101, Finland. ${ }^{3}$ Department of Neurology, Kuopio University Hospital and University of Eastern Finland, Kuopio, Fl-70211, Finland

Published: 15 November 2010

\section{References}

1. Bach J-F: The effect of infections on susceptibility to autoimmune and allergic diseases. N Engl J Med 2002, 347:911-920.

2. Brookmeyer R, Johnson E, Ziegler-Graham K, Arrighi HM: Forecasting the global burden of Alzheimer's disease. Alzheimers Dement 2007, 3:186-191.

3. Qiu C, De Ronchi D, Fratiglioni L: The epidemiology of the dementias: an update. Curr Opin Psychiatry 2007, 20:380-385.

4. Ferri CP, Prince M, Brayne C, Brodaty H, Fratiglioni L, Ganguli M, Hall K, Hasegawa K, Hendrie H, Huang Y, Jorm A, Mathers C, Menezes PR, Rimmer E, Scazufca M: Global prevalence of dementia: a Delphi consensus study. Lancet 2005, 366:2112-2117.

5. Forstl H, Kurz A: Clinical features of Alzheimer's disease. Eur Arch Psychiatry Clin Neurosci 1999, 249:288-290.

6. Backman L, Jones S, Berger AK, Laukka EJ, Small BJ: Multiple cognitive deficits during the transition to Alzheimer's disease. J Intern Med 2004, 256:195-204.

7. Petersen RC, Stevens JC, Ganguli M, Tangalos EG, Cummings JL, DeKosky ST: Practice parameter: early detection of dementia: mild cognitive impairment (an evidence-based review). Report of the Quality Standards Subcommittee of the American Academy of Neurology. Neurology 2001, 56:1133-1142.

8. Gauthier S, Reisberg B, Zaudig M, Petersen RC, Ritchie K, Broich K, Belleville S,

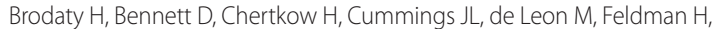
Ganguli M, Hampel H, Scheltens P, Tierney MC, Whitehouse P, Winblad B: Mild cognitive impairment. Lancet 2006, 367:1262-1270.

9. Laws SM, Hone E, Gandy S, Martins RN: Expanding the association between the APOE gene and the risk of Alzheimer's disease: possible roles for APOE promoter polymorphisms and alterations in APOE transcription. J Neurochem 2003, 84:1215-1236.

10. Polvikoski T, Sulkava R, Haltia M, Kainulainen K, Vuorio A, Verkkoniemi A, Niinisto L, Halonen P, Kontula K: Apolipoprotein E, dementia, and cortical deposition of beta-amyloid protein. N Engl J Med 1995, 333:1242-1247.

11. Hardy JA, Higgins GA: Alzheimer's disease: the amyloid cascade hypothesis Science 1992, 256:184-185.

12. Rapoport M, Dawson HN, Binder LI, Vitek MP, Ferreira A: Tau is essential to beta-amyloid-induced neurotoxicity. Proc Natl Acad Sci USA 2002, 99:6364-6369.

13. Mudher A, Lovestone S: Alzheimer's disease-do tauists and baptists finally shake hands? Trends Neurosci 2002, 25:22-26.

14. Mattsson N, Zetterberg H, Hansson O, Andreasen N, Parnetti L, Jonsson M, Herukka SK, van der Flier WM, Blankenstein MA, Ewers M, Rich K, Kaiser E, Verbeek M, Tsolaki M, Mulugeta E, Rosen E, Aarsland D, Visser PJ, Schroder J, Marcusson J, de Leon M, Hampel H, Scheltens P, Pirttila T, Wallin A, Jonhagen 
ME, Minthon L, Winblad B, Blennow K: CSF biomarkers and incipient Alzheimer disease in patients with mild cognitive impairment. JAMA 2009, 302:385-393.

15. De Meyer G, Shapiro F, Vanderstichele $H$, Vanmechelen E, Engelborghs $S$, De Deyn PP, Coart E, Hansson O, Minthon L, Zetterberg H, Blennow K, Shaw L, Trojanowski JQ, for the Alzheimer's Disease Neuroimaging Initiative: Diagnosis-independent Alzheimer disease biomarker signature in cognitively normal elderly people. Arch Neurol 2010, 67:949-956.

16. Marksteiner J, Hinterhuber H, Humpel C: Cerebrospinal fluid biomarkers for diagnosis of Alzheimer's disease: beta-amyloid(1-42), tau, phosphotau-181 and total protein. Drugs Today (Barc) 2007, 43:423-431.

17. Borroni B, Di Luca M, Padovani A: Predicting Alzheimer dementia in mild cognitive impairment patients. Are biomarkers useful? Eur J Pharmacol 2006, 545:73-80.

18. Tarawneh R, Holtzman DM: Biomarkers in translational research of Alzheimer's disease. Neuropharmacology 2010, 59:310-322.

19. Schroeter ML, Stein T, Maslowski N, Neumann J: Neural correlates of Alzheimer's disease and mild cognitive impairment: a systematic and quantitative meta-analysis involving 1351 patients. Neuroimage 2009, 47:1196-1206.

20. Ransohoff DF: Rules of evidence for cancer molecular-marker discovery and validation. Nat Rev Cancer 2004, 4:309-314

21. Ransohoff DF: Bias as a threat to the validity of cancer molecular-marker research. Nat Rev Cancer 2005, 5:142-149.

22. Ray S, Britschgi M, Herbert C, Takeda-Uchimura Y, Boxer A, Blennow K, Friedman LF, Galasko DR, Jutel M, Karydas A, Kaye JA, Leszek J, Miller BL, Minthon L, Quinn JF, Rabinovici GD, Robinson WH, Sabbagh MN, So YT, Sparks DL, Tabaton M, Tinklenberg J, Yesavage JA, Tibshirani R, Wyss-Coray T: Classification and prediction of clinical Alzheimer's diagnosis based on plasma signaling proteins. Nat Med 2007, 13:1359-1362.

23. O'Bryant SE, Xiao G, Barber R, Reisch J, Doody R, Fairchild T, Adams P, Waring S, Diaz-Arrastia R: A serum protein-based algorithm for the detection of Alzheimer disease. Arch Neurol 2010, 67:1077-1081.

24. Schipper HM, Maes OC, Chertkow HM, Wang E: MicroRNA expression in Alzheimer blood mononuclear cells. Gene Regul Syst Bio 2007, 1:263-274.

25. Maes OC, Xu S, Yu B, Chertkow HM, Wang E, Schipper HM: Transcriptional profiling of Alzheimer blood mononuclear cells by microarray. Neurobiol Aging 2007, 28:1795-1809.

26. Lenz EM, Bright J, Wilson ID, Hughes A, Morrisson J, Lindberg H, Lockton A: Metabonomics, dietary influences and cultural differences: a 1H NMRbased study of urine samples obtained from healthy British and Swedish subjects. J Pharm Biomed Anal 2004, 36:841-849.

27. Velagapudi VR, Hezaveh R, Reigstad CS, Gopalacharyulu PV, Yetukuri L, Islam S, Felin J, Perkins R, Boren J, Oresic M, Backhed F: The gut microbiota modulates host energy and lipid metabolism in mice. J Lipid Res 2010, 51:1101-1112.

28. Nikkilä J, Sysi-Aho M, Ermolov A, Seppänen-Laakso T, Simell O, Kaski S, Oresic $\mathrm{M}:$ Gender dependent progression of systemic metabolic states in early childhood. Mol Syst Biol 2008, 4:197.

29. Illig T, Gieger C, Zhai G, Romisch-MargI W, Wang-Sattler R, Prehn C, Altmaier E, Kastenmuller G, Kato BS, Mewes H-W, Meitinger T, de Angelis MH, Kronenberg F, Soranzo N, Wichmann H-E, Spector TD, Adamski J, Suhre K: A genome-wide perspective of genetic variation in human metabolism. Nat Genet 2010, 42:137-141.

30. Oresic M, Vidal-Puig A, Hänninen V: Metabolomic approaches to phenotype characterization and applications to complex diseases. Expert Rev Mol Diagn 2006, 6:575-585

31. HUSERMET: Human Serum Metabolome in Health and Disease [http://www.husermet.org/]

32. PredictAD [http://www.predictad.eu/]

33. Bertram L, Tanzi RE: Thirty years of Alzheimer's disease genetics: the implications of systematic meta-analyses. Nat Rev Neurosci 2008, 9:768-778,

34. De Ferrari GV, Papassotiropoulos A, Biechele T, Wavrant De-Vrieze F, Avila ME, Major MB, Myers A, Saez K, Henriquez JP, Zhao A, Wollmer MA, Nitsch RM, Hock C, Morris CM, Hardy J, Moon RT: Common genetic variation within the lowdensity lipoprotein receptor-related protein 6 and late-onset Alzheimer's disease. Proc Natl Acad Sci USA 2007, 104:9434-9439.

35. Kimchi-Sarfaty C, Oh JM, Kim IW, Sauna ZE, Calcagno AM, Ambudkar SV, Gottesman MM: A "silent" polymorphism in the MDR1 gene changes substrate specificity. Science 2007, 315:525-528.

36. Oresic M, Shalloway D: Specific correlations between relative synonymous codon usage and protein secondary structure. J Mol Biol 1998, 281:31-48.
37. Selkoe DJ: Cell biology of protein misfolding: the examples of Alzheimer's and Parkinson's diseases. Nat Cell Biol 2004, 6:1054-1061.

38. Thinakaran G, Koo EH: Amyloid precursor protein trafficking, processing, and function. J Biol Chem 2008, 283:29615-29619.

39. Jang H, Arce FT, Ramachandran S, Capone R, Azimova R, Kagan BL, Nussinov R, Lal R: Truncated beta-amyloid peptide channels provide an alternative mechanism for Alzheimer's Disease and Down syndrome. Proc Natl Acad Sci USA 2010, 107:6538-6543

40. Brites P, Waterham HR, Wanders RJA: Functions and biosynthesis of plasmalogens in health and disease. Biochim Biophys Acta 2004, 1636:219-231.

41. Farooqu AA, Horrocks LA: Plasmalogens, phospholipase A2, and docosahexaenoic acid turnover in brain tissue. J Mol Neurosci 2001, 16:263272; discussion 279-284.

42. Nagan N, Zoeller RA: Plasmalogens: biosynthesis and functions. Prog Lipid Res 2001, 40:199-229.

43. Goodenowe DB, Cook LL, Liu J, Lu Y, Jayasinghe DA, Ahiahonu PW, Heath D, Yamazaki Y, Flax J, Krenitsky KF, Sparks DL, Lerner A, Friedland RP, Kudo T, Kamino K, Morihara T, Takeda M, Wood PL: Peripheral ethanolamine plasmalogen deficiency: a logical causative factor in Alzheimer's disease and dementia. J Lipid Res 2007, 48:2485-2498.

44. Han X, Holtzman DM, McKeel DW Jr: Plasmalogen deficiency in early Alzheimer's disease subjects and in animal models: molecular characterization using electrospray ionization mass spectrometry. J Neurochem 2001, 77:1168-1180

45. Farooqui AA, Rapoport SI, Horrocks LA: Membrane phospholipid alterations in Alzheimer's disease: deficiency of ethanolamine plasmalogens. Neurochem Res 1997, 22:523-527.

46. Maeba R, Maeda T, Kinoshita M, Takao K, Takenaka H, Kusano J, Yoshimura N, Takeoka Y, Yasuda D, Okazaki T, Teramoto T: Plasmalogens in human serum positively correlate with high-density lipoprotein and decrease with aging. J Atheroscler Thromb 2007, 14:12-18.

47. Su B, Wang X, Nunomura A, Moreira Pl, Lee HG, Perry G, Smith MA, Zhu X: Oxidative stress signaling in Alzheimer's disease. Curr Alzheimer Res 2008, 5:525-532.

48. Oresic M, Hanninen VA, Vidal-Puig A: Lipidomics: a new window to biomedical frontiers. Trends Biotechnol 2008, 26:647-652.

49. Miller Y, Ma B, Nussinov R: Polymorphism in Alzheimer Abeta amyloid organization reflects conformational selection in a rugged energy landscape. Chem Rev 2010, 110:4820-4838.

50. Yu X, Wang J, Yang JC, Wang Q, Cheng SZ, Nussinov R, Zheng J: Atomic-scale simulations confirm that soluble beta-sheet-rich peptide self-assemblies provide amyloid mimics presenting similar conformational properties. Biophys J 2010, 98:27-36.

51. Niemelä PS, Ollila S, Hyvönen MT, Karttunen M, Vattulainen I: Assessing the nature of lipid raft membranes. PLoS Comput Biol 2007, 3:e34

52. Yetukuri L, Söderlund S, Koivuniemi A, Seppänen-Laakso T, Niemelä PS, Hyvönen M, Taskinen MR, Vattulainen I, Jauhiainen M, Oresic M: Composition and lipid spatial distribution of HDL particles in subjects with low and high HDL-cholesterol. J Lipid Res 2010, 51:2341-2351.

53. Searls DB: Data integration: challenges for drug discovery. Nat Rev Drug Discov 2005, 4:45-58.

54. Meyer-Lindenberg A, Weinberger DR: Intermediate phenotypes and genetic mechanisms of psychiatric disorders. Nat Rev Neurosci 2006, 7:818-827.

55. Underwood BR, Broadhurst D, Dunn WB, Ellis DI, Michell AW, Vacher C, Mosedale DE, Kell DB, Barker RA, Grainger DJ, Rubinsztein DC: Huntington disease patients and transgenic mice have similar pro-catabolic serum metabolite profiles. Brain 2006, 129:877-886.

56. Götz J, Streffer JR, David D, Schild A, Hoerndli F, Pennanen L, Kurosinski P, Chen F: Transgenic animal models of Alzheimer's disease and related disorders: histopathology, behavior and therapy. Mol Psychiatry 2004, 9:664-683.

57. Lotjonen JM, Wolz R, Koikkalainen JR, Thurfjell L, Waldemar G, Soininen H, Rueckert D: Fast and robust multi-atlas segmentation of brain magnetic resonance images. Neuroimage 2010, 49:2352-2365.

58. ETHERPATHS [http://www.etherpaths.org].

doi:10.1186/gm204

Cite this article as: Orešič M, et al.: Systems medicine and the integration of bioinformatic tools for the diagnosis of Alzheimer's disease. Genome Medicine 2010, 2:83. 